\title{
Migration across Spanish Provinces: Evidence from the Social Security Records (1978-1992)
}

\author{
Carlo Devillanova*and Walter García-Fontes ${ }^{\dagger}$
}

September 3, 1998

\begin{abstract}
This paper uses Social Security records to study internal migration in Spain. This is the first paper that uses this data source, which has some advantages with respect to existing data sources: it includes only job-seeking migrants and it allows to identify temporary migration.

Within the framework of an extended gravity model, we estimate a Generalized Negative Binomial regression on gross migration flows between provinces. We quantify the effect of local labor market imbalances on workers' mobility and discuss the equilibrating role of internal migration in Spain. Our main results show that the effect of employment opportunities have changed after 1984; migrants seem to be more responsive to economic conditions but, consistently with previous studies for the Spanish labor market, the migration response to wage differentials is wrongly signed. Our analysis also confirms the larger internal mobility of highly qualified workers.
\end{abstract}

\section{Introduction}

How do migration flows respond to local economic conditions? Do workers move away from depressed labor markets (relatively high unemployment rates and low wages), thus reducing the geographical mismatch between local labor demand and supply? Do skilled workers behave differently from unskilled workers?

The answer to these questions is important in order to understand the observed migration flows and their effects on regional labor market imbalances. The issue is even more relevant in view of European integration. Indeed, internal migration is expected to be one

\footnotetext{
*Universitat Pompeu Fabra and Università Bocconi. Correspondence: Istituto di Economia Politica, Università Bocconi, via Gobbi 5, 20136 Milano, Italy. E-mail: carlo.devillanova@uni.bocconi.it; tel.: $+(0) 2.58365342$; fax: $+(0) 2.58365318$

${ }^{\dagger}$ Universitat Pompeu Fabra, Department of Economics, C/. Ramon Trias Fargas 25-27, 08005 Barcelona, Spain. E-mail: wgarcia@upf.es
} 
of the main vehicles for labor market adjustment in the future European Monetary Union (EMU). Therefore, it is worth exploring whether workers' flows rightly react to economic incentives, thus reducing local imbalances. Moreover, migration flows are likely to behave differently in different countries, due to geographical characteristics, cultural reasons and alternative institutional regimes.

This paper aims to explore the issue by looking at Spain during the period 1978 1992.

The equilibrating role of internal migration has been addressed in a number of studies, based both upon micro-data and aggregate migration flows. There exist excellent surveys on internal migration, starting with the influential work by Greenwood (1975); see Greenwood (1993), Greenwood (1997), Hergoz et al. (1993). In general, the conclusion is that the response of migration to local labor markets imbalances remains ambiguous.

As concerns Spain, the issue has been investigated by Bentolila and Dolado (1991) and Antolín and Bover (1997), by focusing on interregional migration. Bentolila and Dolado, using aggregate migration flows, find that both an increase in a region's relative wage and a fall in its relative unemployment rate cause a (very little) increase of net migration to that region. Antolín and Bover use individual data and get that regional unemployment differential has a strong, wrong-signed effect; they argue that this result is mainly due to the anomaly of registered workers at INEM. They also find that people tend to leave from high real wage regions.

With respect to these works, two main contributions of the paper are worth emphasizing. First, we provide a new data source for studying internal migration in Spain, by using the records of Spanish Social Security. Second, we conduct a more disaggregated analysis by looking at flows between provinces.

We get "wrong" signs in both wage and housing price differentials: workers move to locations with higher housing prices and lower wages. Furthermore, we find that the effect of employment opportunities changed after 1984. For the period 1978-1984 neither the unemployment rate differential nor the growth of employment affect migration flows. However, after 1984 both variables are significant and exhibit the expected sign, although the elasticity to the unemployment rate differential is low. Our analysis also confirms the larger internal mobility of highly qualified workers.

The remainder of the paper is organized as follows: the next section describes the data; section 3 presents the framework of analysis and the regression specification; the results are presented in section 4 . Finally, section 5 concludes. The construction of the data base is explained in appendix 1. Appendix 2 contains all tables and pictures.

\section{The data}

Olano (1990) provides a brief description of the main statistical sources for studying internal migration in Spain. They are: general census (Censos de la población de España and Padrón municipal de habitantes), used, among others, by Olano himself and Ródenas 
(1994); data on residential changes (National Institute of Statistic, INE), used, for instance, by Bentolila and Dolado (1991); Spanish Labor Force Survey (Encuesta de Población Activa, thereafter EPA), which has been used by Antolín and Bover (1997); finally, migration can be studied as a residual variable, as in Bentolila and Jimeno (1995), where the behavior of migration is captured by the difference between the change in employment, on the one hand, and those of unemployment and participation, on the other ${ }^{1}$.

In this paper we provide a new piece of evidence for studying internal workers' mobility in Spain, using the records of Spanish Social Security (Cuentas de Cotización de la Seguridad Social, Fichero Técnico de Cuentas de Cotización).

For each match between firm and employee the records provide the location of the firm; by checking changes through the working history of employees, we can reconstruct their movements.

Special attention should be payed to the meaning of labor mobility in this context. Indeed, workers are registered as migrants only when they find a job in a new province: at some moment in time we observe a worker employed in province $i$; afterwards, the same worker is observed to be employed in province $j$. In this case we say that the worker migrates.

One consequence of this denotation of migration is that we actually do not know when migration occurs. It can be the case that a worker migrates from $i$ to $j$ at the beginning of his/her unemployment spell (the time lag between job in $i$ and job in $j$ ), but we only observe this movement when the new match occurs. This discrepancy can be relevant when unemployment spells are large. As an extreme case, migrants who never find a job in the province of destination are not observed at all. Workers who get their first job by migrating to a new province are not counted either.

From this definition of migration, other more appealing consequences follow.

First of all, our measure of mobility includes temporary migration. Generally, administrative data do not record short-run migration (people do not need to change residence). In the "Survey on Migration Flows" (Encuesta de Flujos Migratorios) from EPA, migration is defined by referring to previous year place of residence. People are asked whether they changed residence in the last year. As a consequence, if a worker gets a temporary job in another province, but returns within the year, this is not recorded as migration in EPA. On the contrary, it is recorded twice in our data, both when the migrant leaves the province and when he/she returns. In fact, the study of temporary migration might be as important as long-run migration. Moreover, Spain experienced a dramatic increase in the proportion of temporary jobs after the 1984 labor market reform ${ }^{2}$.

A second remarkable feature of the data is that they only take into account job-seeking migration. People move for many different reasons or combinations of reasons (quality

\footnotetext{
${ }^{1}$ Indirect evidence of workers mobility across Spanish regions can also be fund in Castillo el al. (1998).

${ }^{2}$ Temporary workers comprised $10 \%$ of total employment in 1983 , the year before the reform. In 1992 , the proportion had reached $33 \%$ of total employment; cfr. Aguirregabiria and Alonso-Borrego (1998) and Segura et al. (1991).
} 
of life, family links, for studying) other than as a reaction to local economic conditions. Of course, one expects factors influencing migration to differ between people seeking to change employment (and residence, if necessary) and people moving for other reasons. This problem, known in the literature as multi-stream migration ${ }^{3}$, is often handled by restricting the analysis to a subset of flows, which are expected to be more homogeneous in this respect. In particular, long-distance (interregional) migration is expected to be mostly determined by job-seeking reasons, while short distance (intra-regional) migration, by residential choices ${ }^{4}$. However, this identification strategy might rise some problems.

First of all, a large proportion of long-distance migration is not determined by jobseeking reasons. For instance, Bentolila and Dolado (1991) look at migration across Spanish regions (long distance migration) and find that $60 \%$ of migrants were "nonactive", which means that the majority of interregional migrants were not seeking a job.

Second, during the 1980's the path of regional development in Spain has been much less sharp than before the oil crisis. The impact of the crisis has not been homogenous across regions and, within regions, across provinces. It is conceivable that job-seeking types of migration progressively shifted to short-distance mobility, especially if the cost of migration is related to distance.

Because of the narrow definition of mobility, our data are almost exempted from the problem of heterogeneity of migration streams.

From these original data we construct a panel of migration flows, by counting the number of migrants - as defined above - between provinces every two years. We do not use yearly flows both in order to reduce the dimensionality of the data-set and to make the data comparable with disposable provincial figures, which are available in odd numbered years.

Previous studies ${ }^{5}$ find that internal migration in developed countries is mostly migration of high-skilled workers. For this reason, we distinguish migration flows according to workers' qualification. Workers are grouped into four categories ${ }^{6}$ : types from 1 to 3 are in descending order of qualification; type 4 are pensioners.

For each year, and each qualification, the square matrix of gross flows has 50 rows, corresponding to the Spanish provinces (Ceuta and Melilla were excluded from the analysis); the entries in the diagonal, which we later ignore, are zero by definition.

The panel of migration flows has 80,000 observations ( 8 biannual dates from 1978 to 1992, by 4 qualification groups, by 50 multiplied by 50 province pairs). Thereafter, $M_{i j t}^{q}$ indicates the number of migrants of category $q$ from province $i$ to province $j$ at time $t$ and $T O T_{i t}^{q}$ the total number of registered workers of category $q$ in province $i$ at time $t$, where, $q=1, \ldots, 4, t=1978,1980, \ldots, 1992$ and $i, j=1, \ldots, 50$.

\footnotetext{
${ }^{3}$ See Gordon (1991).

${ }^{4}$ Cfr. Molho (1984).

${ }^{5}$ See, for instance, Antolín, Bover (1993), Bean et al. (1990), Burda, Wyplosz (1992), Huges, McCormick (1994), Shioji (1995).

${ }^{6}$ See appendix 1.
} 
The data base for our analysis is constructed by crossing this information coming from records from the Spanish Social Security with provincial data provided by Fundación BBV, as explained in Appendix 1. We use provincial information with a lag, to reduce endogeneity problems with right-hand variables. That is, we cross the 1977 provincial data with 1978 migration flows, 1979 provincial data with 1980 flows, and so on.

\subsection{Remarks on the specification of the dependent variable}

The dependent variable of our analysis is, hence, gross interprovincial migration flows. This choice raises issues of data availability, econometrics tools and computational dimensionality. Thus it is worth justifying our choices.

Interprovincial migration. We look at migration across provinces (Spanish "Provincias"), while previous works ${ }^{7}$ focus on interregional migration (Spanish "Comunidades Autónomas").

A first reason for a more disaggregated analysis is that we do not want to lose information. As noted by Olano (1990) and Ródenas (1994), there has been a relative increase of short-distance migration beginning from the early 1970's. We find that more than $25 \%$ of migration takes place across provinces within the same region.

More importantly, as already noted the path of economic development during the last 20 years is not homogeneous within regions of Spain: some provinces took-off after the second oil crisis ${ }^{8}$. If, as seems plausible, the cost of migration increases with distance, people might optimally choose to move to a province within the same region. In other word, we suspect that the dichotomy short-distance/long-distance migration does not really enable to get rid of the multi-streams nature of migration. Again, our narrow definition of mobility allows us to disregard the problem.

Gross flows. We will argue that gross and net migration flows have a quite different behavior. Restricting the analysis to the latter would entail a substantial loss of information.

Bilateral flows. Our dependent variable is $M_{i j t}^{q}(j \neq i)$, the number of migrants from each province $i$ to any of the other 49 provinces. Two main reasons justify this choice.

First, as pointed out by Huges and McCormick (1994), the decision to emigrate is not independent of the destination choice: "even if you are not interested in destination choice, it is a miss-specification to estimate the equation (for the probability of migration) without taking account of the attractiveness of the alternatives".

Second, by looking at bilateral flows we can express market incentives for migration in terms of the relative attractiveness of the destination with respect to the location of origin. Previous studies ${ }^{9}$ regress migration on the difference between local variables

\footnotetext{
${ }^{7}$ See Antolín, Bover (1997), Castillo et al. (1998), Bentolila and Dolado (1991), Bentolila, Jimeno (1995).

${ }^{8}$ References in Ródenas (1994).

${ }^{9}$ See Antolin, Bover (1997) and Bentolila, Dolado (1991).
} 
and nationwide levels. A first shortcoming is that this kind of analysis does not allow one to pick-up pull factors of migration (features of the destination areas which attract immigrants).

Still, it is not clear why the local push factors (characteristics of the origin areas which generate out-migration) should be caught either. The reason is, once again, that moving is costly and the cost of migration is likely to increase with distance. With only two regions this observation is pointless, but with more than one possible destination, the attractiveness of alternatives depends on their relative distance ${ }^{10}$.

\subsection{A descriptive analysis of migration flows}

This subsection is intended to offer a description of the migration flows, which provides guidance for the rest of the work.

Along the whole period, we observe 15,293 migrants over 678,695 total registered workers. This is approximately $2.25 \%$ of the sample, a value higher than what one gets by looking at other sources.

The annual emigration rates elaborated by Ródenas (1994), using data from INE, reached at most $1.69 \%$ in 1989 , the last year of the sample. Two reasons could help explain the difference. First, as already noted, official data from INE fail to take into account temporary migration; this inevitably underestimates the scale of migration. Second, the migration rate computed by Ródenas refers to the whole population; in fact, the active population is more mobile than the non-active population ${ }^{11}$, and this too can explain part of the observed difference.

The discrepancy is huge when compared with the findings of Antolin, Bover (1997). The two authors use pooled cross-sections form EPA, for the period 1987-91. From a sample of 224,714 individuals they find only 664 migrants, which means $0.295 \%$. Since Antolín and Bover are concerned with interregional migration, we checked whether this difference is due to higher interprovincial mobility, relative to interregional mobility. However, the rate of interregional mobility is still 1.68\% (11,453 migrations across regions). Even when we focus on the last two periods of our sample (the period considered by Antolin and Bover) figures change only slightly.

Table 1 provides the numbers of interregional and interprovincial migrants by qualifications. The resulting picture is a labor market much more integrated for high skilled workers than for the others workers; this is a well known feature of internal migration in developed countries. Pensioners do not show great mobility.

\section{Table 1}

\footnotetext{
${ }^{10}$ Feder's aggregation method solves the problem by collapsing the information in all other provinces into a single variable, using distance between $i$ and $j\left(d_{i j}\right)$ as a weighting mechanism. Cfr. Feder (1980), Foot, Milne (1990) and Milne (1991).

${ }^{11}$ Ródenas (1991), pag. 252.
} 
We compute the rate of out-migration by qualification, $E M R A T E_{i t}^{q}=\frac{\sum_{J} M_{i j t}^{q}}{T O T_{i t}^{q}}$, the total number of emigrants from a province $i$ divided by the total number of affiliates in that province, and the rate of immigration $I M R A T E_{j t}^{q}=\frac{\sum_{i} M_{i j t}^{q}}{T O T_{j t}^{q}}$, the total number of immigrants to a province $j$, divided by the total number of affiliates in that province.

\section{Table 2}

Workers of qualification 1 not only display a higher average rate of migration (near double with respect to qualification 3 ), but also a much higher standard deviation (see table 2).

Figure 1 plots the rate of out-migration. It is worth noting that migration is highly pro-cyclical for all groups but pensioners. Figure 2 plots the national unemployment rate. Low mobility is associated with high unemployment rates: during recessions flows are reduced; on the other hand, internal migration increases during economic recovery ${ }^{12}$. It seems that the recession of the early 90's reduced migration flows.

One clear feature of our data is that relatively high gross outflows and inflows generate very small net flows. In our sample, the average rate of net immigration (defined for each province as the total number of immigrants minus the total number of emigrants, divided by the number of affiliates) is of the order of 0.002 for workers of qualification 1 and 2 and 0.0007 for workers of qualification three. In other words, migration goes in both directions: on average, provinces with large outflows also have comparable inflows of workers of the same qualification. This is what in the literature is known as the Lowry effect.

In Spain, the Lowry effect emerged only recently ${ }^{13}$. Bentolila and Dolado (1991), analyzing migration flows in between 1962 and 1986, claim that the unidirectionality of flows makes gross and net migration behave quite comparably for most of the period. However, they find a clear pattern only until 1976.

The absence of any strong unidirectionality of workers' flows can also be seen by looking at the cross correlations matrix of the immigration and emigration rates (table 3 ). Indeed, one finds a relatively strong correlation of inflows and outflows of workers of the same category. It runs from 0.43 for qualification 2 until 0.82 for qualification 3 . The exception is the correlation between immigration and emigration rates for pensioners, which is not statistically significant at the $5 \%$ level.

\section{table 3}

A second fact emerges from table 3, flows differ according to workers' qualification. The correlation of immigration (and emigration) rates of different types of workers are surprisingly low. For instance, the correlation between the immigration rate of workers

\footnotetext{
${ }^{12}$ Same finding in Ródenas (1994). The author shows that the decade 1960-70 was characterized by very high mobility; a reduction of mobility took place in the 1970s, especially during the period 1971-75. In between 1986 and 1989 migration was even higher than during the 60's.

${ }^{13}$ Olano (1990) was perhaps the first in recording the new pattern of internal migration in Spain.
} 
of qualification 1 and qualification 2 is 0.17 . Again, pensioners behave differently: the correlation of their immigration and emigration rate with migration of other categories of workers is either statistically insignificant or negative.

This observation have also a direct impact on net flows. Net flows are defined as the total number of immigrants to a province minus total number of emigrants from the same province, distinguished by qualification

$$
N E T_{i t}^{q}=\sum_{j} M_{j i t}^{q}-\sum_{j} M_{i j t}^{q}
$$

The correlation of net migration flows across qualifications is extremely low (see table 4).

Table 4 and 5

This feature does not change by considering net migration during the whole period. The correlation between total net flows, obtained by summing net flows over time, for different qualifications is very low or even negative (see table 5).

Two main facts emerge from this descriptive section. First, interprovincial migration exhibits a strong Lowry effect and net flows are much lower than gross flows. Second, workers' qualifications affect their mobility decisions; we will further explore the issue later in the paper.

As an example, let's look at two big cities, Barcelona and Madrid.

\section{Table 6 and 7}

Both Barcelona and Madrid have negative net flows (see table 6). However, if we look at the balance for the 4 different groups, they behave quite differently. Barcelona gained 29 workers of qualification 1, while the net-flows are negative for the other three groups. On the other hand, Madrid lost 118 workers of qualification 1 and 2, and this is offset by a net arrival of 110 workers of low qualification 3 .

Table 7 gives the flavor of the Lowry effect - gross flows which goes both ways - for Madrid only, but this also occurs for almost all Spanish provinces.

\section{Framework of Analysis}

Internal migration can be described by means of a square matrix, whose rows and columns are locations within a country. The element $(i j)$ represents the number of migrants from location $i$ to location $j, M_{i j}$ (in this section the indexes for year and qualification were suppressed in order to simplify the notation). Some regularities have been observed within this framework. Namely, the matrix has larger values for migration between large places and/or in correspondence of locations which are geographically closer. 
The baseline gravity model tries to capture these regularities by modelling $M_{i j}$ as directly proportional to the population size of areas $\left(P_{i}\right.$ and $\left.P_{j}\right)$ and inversely proportional to the distance $\left(d_{i j}\right)$. Assuming multiplicative errors and taking logarithms one gets

$$
\ln \left(M_{i j}\right)=\mu_{0}+\mu_{1} \ln \left(P_{i}\right)+\mu_{2} \ln \left(P_{j}\right)+\mu_{3} \ln \left(d_{i j}\right)+\varepsilon_{i j}
$$

where the $\mu$ 's are coefficients. Treating $\ln \left(M_{i j}\right)$ as a continuous variable and assuming errors to be log-normally distributed, the model can be estimated by means of standard econometric tools ${ }^{14}$.

However, a trivial feature of the migration matrix is that the larger the number of locations considered, the greater the proportion of zero and of very small values. A small positive constant should be added to zero flows so that logarithms are defined, but then parameter estimates strongly depend on the choice of the constant. Moreover, with very small flows the dependent variable is clearly discrete in nature. The Poisson regression model improves on the log-linear model by taking into account these characteristics. The Poisson regression model specifies the probability of $M_{i j}$ persons moving from origin $i$ to destination $j$ as drawn from a Poisson distribution with parameter $\lambda_{i j}$

$$
\operatorname{prob}\left(M_{i j}\right)=\frac{e^{-\lambda_{i j}} \lambda_{i j}^{M_{i j}}}{M_{i j} !} \quad M_{i j}=0,1,2, \ldots
$$

$\lambda_{i j}$ is the mean of the distribution and can be related to a set of regressors $X_{i j}$, still to be specified

$$
\ln \left(\lambda_{i j}\right)=\mu X_{i j}
$$

where $\mu$ is the vector of parameters.

One implicit assumption of the Poisson model is that the variance of $M_{i j}$ equals its mean $\lambda_{i j}$. In fact, migration flows often show a greater variability than expected under the Poisson model. This situation is denoted in the literature as overdispersion, or extraPoisson variation.

Many reasons can explain overdispersion in the data ${ }^{15}$. It may be caused because the model does not include all the relevant explanatory variables, or because the covariates, which are typically represented by averages (of wages, housing prices, unemployment) of the areas, might not succeed in capturing the variance of individuals' opportunities. Finally, the Poisson model assumes that migration events are independent over time, over space (absence of clustering) and between individual movers. Violation of any of these assumption leads to a violation of the Poisson variance assumption. This last problem becomes even more serious when the Poisson regression pools bilateral flows over time periods ${ }^{16}$, as in our study.

\footnotetext{
${ }^{14}$ The model has been extended in order to include other variables affecting migration; see Molho (1984).

${ }^{15}$ For an exhaustive review of the topic, see Congdon (1993) and Winkelmann and Zimmermann (1995).

${ }^{16}$ Cfr. Congdon (1993).
} 
In the presence of extra-Poisson variation, the assumption that data are Poisson affects the estimates and results in wrong (overstated) significance levels of the independent variables.

In fact, we checked whether our migration flows are Poisson distributed, and the comparison of the chi-squared goodness-of-fit statistic with disposable degrees of freedom indicates the presence of strong overdispersion in the sample.

A common solution to overdispersion is to use a Negative Binomial model. This model introduces an extra-variation in the Poisson model. More precisely, count data of migrants are assumed to be generated, as before, by a Poisson process

$$
\operatorname{prob}\left(M_{i j}\right)=\frac{e_{i j}^{-\tilde{\lambda}_{i j}} \tilde{\lambda}^{M_{i j}}}{M_{i j} !} \quad M_{i j}=0,1,2, \ldots
$$

where now

$$
\ln \left(\tilde{\lambda}_{i j}\right)=\ln \left(\lambda_{i j}\right)+u_{i j}=\mu X_{i j}+u_{i j}
$$

$u_{i j}$ is an error term, with

$$
e^{u_{i j}} \sim \operatorname{Gamma}\left(\frac{1}{\alpha}, \frac{1}{\alpha}\right)
$$

Since $E\left[u_{i j}\right]=1$, the expected value of the migration random variable remains $\lambda_{i j}=$ $\mu X_{i j}$. What changes is its variance, which becomes $\lambda_{i j}+\lambda_{i j}^{2} \alpha . \alpha$ is called the overdispersion parameter; the larger $\alpha$, the greater the overdispersion. If $\alpha$ is zero, than the Negative Binomial model collapses in the Poisson model.

In the baseline model $\mu X_{i j}=\mu_{0}+\mu_{1} \ln \left(P_{i}\right)+\mu_{2} \ln \left(P_{j}\right)+\mu_{3} \ln \left(d_{i j}\right)$. More generally, the model can be extended to include variables found to be important from the human capital model of migration.

\subsection{A simple human capital model of migration}

Define $V_{i}$ the value function of an individual living in location $i$, which can decide whether to move to location $j$ or to remain

$$
V_{i}=\operatorname{Max}\left\{u\left(y_{i}\right)+E\left[V_{i}^{\prime}\right] ; u\left(y_{i}-c\right)+E\left[V_{j}^{\prime}\right]\right\}
$$

where $u(\cdot)$ is the individual's utility function, $y_{i}$ is income, $c$ is the cost of migration and the prime refers to next period value function. Migration is optimal as long as the difference between the expected value function of being in location $j$ and that of staying at home is greater then the loss in utility due to migration cost:

$$
u\left(y_{i}\right)-u\left(y_{i}-c\right) \leq E\left[V_{j}^{\prime}\right]-E\left[V_{i}^{\prime}\right]
$$


The empirical strategy is to assume that the comparison between the value function of leaving and the value function of staying is done in terms of observable characteristics of locations $X_{j}$ and $X_{i}$. Assuming that the utility function is linear, then migration is optimal if its cost is less or equal to the expected gains: $c \leq f_{j}\left(X_{j}\right)-f_{i}\left(X_{i}\right)$. The probability of migrating is going to be a function of observable characteristics of locations $X_{i}$ and $X_{j}$, and the cost of migration.

With a more general concave utility function, the cost of migration would be inversely related to income $y_{i}$ : the lower income is, the more valuable the loss of resources due to migration. In this case migration takes place when $u\left(y_{i}\right)-u\left(y_{i}-c\right) \leq f_{j}\left(X_{j}\right)-f_{i}\left(X_{i}\right)$.

The human capital model of migration provides testable conditions under which it is optimal to migrate. However, as already stressed, we only observe migration when the migrant finds a new job in the province of destination. In other words, when the cost of migration is less or equal to the expected gains, an individual optimally decides to look for a job in the other location.

Following Jackman and Savouri (1992), here migration can be viewed as the consequence of a successful job search for (re-)employment, rather than as a pre-condition for it. Vanderkamp (1977) shows that an aggregate migration function of the gravity type emerges from a search model in which migration is seen as a response to information about vacancies in other locations.

\subsection{Regression specification}

Finally, we run a Generalized Negative Binomial regression, which performs a maximum likelihood estimation of (1)-(2)-(3), where the logarithm of the overdispersion parameter $\alpha$ is allowed to vary across observations as a linear combination of a set of covariates $z_{i j}$

$$
\ln \alpha=\delta z_{i j}
$$

The sample is split into two sub-samples, each of four periods. The first sub-sample pools together 4 cross-sections, from 1978 to 1984; the second, the remaining 4 cross-sections, from 1986 to 1992. The likelihood ratio test for equal distribution of the two periods allows us to reject the hypothesis of identical distributions at any level of significance.

The dependent variable is $M_{i j t}^{q}$, the number of workers of qualification $q$ moving at time $t$ from province $i$ to province $j$.

All regressors are in logarithms, thus allowing for a direct interpretation of the results in terms of elasticities.

Let's begin with the regressors for the mean of the distribution $\left(X_{i j t}\right)$. We include the distance between provinces, $d_{i j}$.

The size of origin and destination is measured by the total number of registered workers in the provinces $\left(T O T_{i t}^{q}\right.$ and $\left.T O T_{j t}^{q}\right)$. Population size can itself influence migration if people care about the dimension of the province (for instance, big cities could be preferred because of the easier access to services). Moreover, the total number of vacancies arising 
in a province $j$ is proportional to $j$ 's population size, because of the natural turnover of its labor force ${ }^{17}$. Since we do not have data on vacancies by provinces, they are proxied by population size.

The variables describing economic conditions at origin relative to destination are the ratio (origin/destination) in: housing rental prices, weight of the agricultural sector, weight of the services sector, wage rate, unemployment rate and percentage change of employment. By taking the logarithms of the ratios, we are constraining the effect of economic variables to be the same at the origin and destination. This specification allows for an immediate interpretation in terms of the equilibrating role of migration.

We also include income per-capita in the province of origin. Per-capita income of destination was never found to be statistically significant and is excluded from the final specification.

The ratio of housing rental prices proxies for the cost of living. The next two variables are intended to control for the sectorial composition of the economy. We expect higher employment growth and higher wages in the province of origin to lower out-migration. On the contrary, a higher unemployment rate should increase out-migration.

A dummy variable for each year was included (but not reported in the tables of results), in order to control for the heterogeneity caused by pooling together different periods. They are found to be statistically significant.

Since variables affecting the general attractiveness of each location may have been omitted $^{18}$, we follow the common practice ${ }^{19}$ of including one dummy variable for each province of origin (not reported in the results), which are found to be statistically significant ${ }^{20}$.

We run separate regressions for workers (qualification 1,2 and 3) and pensioners. In the regression for workers, dummy variables are included for different qualifications. We check whether the slopes (and not only the levels) differ across types of workers. The response to economic variables was found to be similar across categories, except for wages, therefore, in the final specification we leave only the interaction variables with wages.

The covariates $z_{i j}$ of the (logarithm of the) overdispersion parameter $\alpha$ are: a constant, the distance, and the population size of origin and destination. We also include dummy variables for qualification 1 and 2, in order to allow for different unexplained variability across categories.

\footnotetext{
${ }^{17}$ Cfr. Vanderkamp (1977).

${ }^{18}$ Actually, the number of factors which have be found significant in explaining migration is extremely large; from climate conditions to local public goods, etc. See Ghatak et al. (1996) for a recent and exaustive survey of the literature.

${ }^{19}$ Cfr. Flowerdew (1991).

${ }^{20}$ This specification fitts better the data than the alternative of using dummy variables for destinations, which we also explored.
} 


\section{Results}

The regression results are reported in tables 8 and 9 of appendix 2. Let's summarize the main finding of our analysis.

A first remark applies to all four regressions (two pooled regressions, for workers and pensioners): the likelihood ratio tests against the hypothesis that data are Poisson distributed clearly rejects that $\alpha$ is equal to zero. This means that data have significant extra-Poisson variation and the Negative Binomial model is the appropriate one.

All the explanatory variables of the overdispersion parameter $\alpha$ are significant ${ }^{21}$. In particular, the unexplained variability increases with distance and decreases with the population size of origin and destination: everything else constant, migration flows are more erratic between small and distant provinces.

The dummies for qualifications are significant in explaining the logarithm of $\alpha$. The extra-Poisson variation is lower the more qualified workers are.

Focusing on the second period (1986-1992) the overall impression is that job opportunities are an important determinant of migration. Workers move away from relatively agricultural provinces to locations with more developed services sectors. A higher unemployment rate, as well as a lower employment growth, prompt people to change province. Note, however, that the elasticity of migration with respect to the unemployment rate, although significant is quite low. Seeking a new job, migrants accept to move to provinces with lower average wage rates and higher housing prices.

The effect of unemployment rate differentials on migration is controversial. Antolín and Bover (1997), analyzing the Spanish labor force survey (EPA), observe a perverse effect of unemployment on migration and argue that this is mainly due to the anomaly of registered workers at INEM. In general, the role of the unemployment rates has been found to be extremely sensitive to the model specification ${ }^{22}$. Thus, our findings need some further qualifications.

First of all, our data set does not say anything about migrants which do not find a new job. A worker who migrates but remains unemployed is not recorded in our sample. Thus our findings are still compatible with those in Antolin and Bover (1997), as long "wrong" migration (to locations with higher unemployment rates) does not result in reemployment.

Second, the results are correct coeteris paribus. In particular, dummy variables for the provinces of origin are found to be statistically significant and to improve the explanatory power of the model.

With respect to wages and housing prices, our analysis may suffer from the low quality of disposable provincial data. The effect of wages is the same that Antolin and Bover (1997) found. One possible explanation of this result is that, in fact, in Spain wages are

\footnotetext{
${ }^{21}$ Except for the regression for pensioners (period 1978-1984).

${ }^{22}$ See Hergoz et al. (1993).
} 
not very responsive to local economic conditions, especially for manual workers ${ }^{23}$. This hypothesis merits further empirical investigation. It is conceivable that the institutional characteristics of the local labor market not only affect whether productivity differentials show-up in wages differentials or unemployment rate differentials, but also the way workers react to those imbalances ${ }^{24}$.

Our analysis warns us of the importance of imperfections in housing markets in discouraging labor reallocation. People who find a job in a new province, on average have to afford higher housing expenditures.

Distance and population size have the expected effect on workers' mobility. Namely, we find that moves are larger between neighboring provinces, and that more populated places attract new workers.

Higher qualified workers are more mobile. The dummy variables for qualification 2 and 3 are significant and negative. This is a very well known feature of internal migration within developed countries. Devillanova (1988) argues that the low mobility of less skilled workers may have perverse effects on the stabilization role of migration.

Some remarkable differences characterize the first pooled regression (1978-1984) with respect to the second one (1986-1992). First, until 1984 the unemployment rate and the change of employment are not statistically significant. Still, sectorial composition affects migration, but the elasticities are lower than in the second period. Second, the constant in the second sub-sample (1986-1992) is double that in the first sub-sample. Finally, the ratio of local wage rates is not significant for workers of qualification 1.

Thus, the equilibrating role of migration is much lower (or even absent) during the period 1978-1984. The interpretation of this result is not obvious. It may be due to the change of the business-cycle conditions (in 1984 the national unemployment rate reached its maximum value of $21.3 \%$ ). A second possible explanation relies on the temporary contracts labor market reform, in 1984 . The reform might have increased internal mobility in Spain.

A final remark can be made on the role of return migration. The conventional wisdom is that migrations from the north of Spain to the poorer Southern regions can be explained by return migration of retired workers. Already Antolín and Bover (1997) find that those perverse migration flows are not particularly affected by people near retirement age. Our analysis confirms that pensioners are a relatively small sub-sample of migrants. Moreover, they do not move to provinces with a higher unemployment rate and/or a greater agricultural sector.

\footnotetext{
${ }^{23}$ See Jimeno (1997).

${ }^{24}$ Note, incidentally, that for the UK Huges and McCormic (1994) found the opposite result: a perverse effect of unemployment rate differentials and a standard role for wages differentials.
} 


\section{Conclusions}

How do migration flows respond to local economic conditions? Do workers move away from depressed labor markets (relatively high unemployment rates and low wages), thus reducing the geographical mismatch between local labor demand and supply? Do skilled workers behave differently from unskilled workers?

This paper tries to answer the above questions by using information from the records of Spanish Social Security. We estimate an extended gravity model by performing a Generalized Negative Binomial regression on gross migration flows between Spanish provinces. Four biannual cross-sections are pooled together, from 1978 to 1984 and from 1986 to 1992.

For the period 1986-1992 we find that job opportunities are an important determinant of migration. Workers move away from relatively agricultural provinces to locations with more developed services sectors. A higher unemployment rate, as well as a lower growth of employment, prompt people to change province. Seeking a new job, migrants accept to move to provinces with lower average wage rates and higher housing prices.

On the other hand, before 1986 unemployment rates and employment growth differentials do not play an important role in driving migration flows. Temporary contract reform in 1984 might have had a positive effect in increasing internal mobility in Spain.

We also find that the market of highly qualified workers is more geographically integrated. However, the response of workers to economic incentive is similar across qualifications.

A direct comparison of these results with the existing literature on internal migration in Spain is not intuitive, both because of the peculiarity of the information contained in the Social Security records and because we choose to look at migration between provinces, while previous studies analyze regional migration out-flows. Future research should repeat a similar exercise for aggregate regional migration flows.

A further line of research, which we are pursuing at the moment, is to look directly at the individual data. 


\section{Appendix 1: The Data}

The data base for this analysis was constructed by crossing information coming from the Spanish Social Security, provincial data from Fundación BBV and distance data computed from maps provided by SAS Institute.

\subsection{Social Security Data}

The original data is a random sample of Social Security Records - Fichero Técnico de Afiliados, Instituto Nacional de la Seguridad Social provided by Centro de Estudios Avanzados en Economía, Universidad Carlos III, see Cardelús-Farré (1993). It has information about 700,000 workers and contains the work history of affiliated workers till July 1993, when the information was downloaded. The total number of records is $4,156,003$, and includes information about periods of employment, periods of illness and out-of-employment when INEM (Instituto Nacional de Empleo) is paying to the Social Security and information about pensioners. The data provided includes information about age of the workers, Spanish province where the worker is affiliate to the Social Security, professional category of the contribution of the worker to the Social Security, dates when the employment spell starts and ends and type of Social Security system for the worker (Régimen General, Régimen Agrario, etc.).

We follow a cleaning strategy similar to García-Fontes and Hopenhayn (1995a and 1995b) and García-Perez (1997). After eliminating incomplete records and keeping only workers affiliated to the General System (Régimen General, we eliminate special systems like Agriculture, Fisheries, and so on; almost all workers, independently of the economic sector where they work, are affiliated to the Régimen General), we keep only spells after 1978. From the remaining records we extract a random sample of 682375 records, corresponding to 140100 workers. Based on these records, and by checking changes in location within the working history of each worker, we construct matrices of migration flows by year and qualification as follows. For year $t(t=78,80, \ldots, 92)$ we compute the total number of affiliates for each qualification in our sample and the total number of corresponding migration events. The ratio between migration events and total affiliates is our migration rate. We define four qualification groups, based on the Social Security tariff of workers, according to the following table: 


\begin{tabular}{|c|c|c|}
\hline "Qualification & "Tariff & "Definition \\
\hline 1 & $\begin{array}{l}1 \\
2 \\
3\end{array}$ & $\begin{array}{l}\text { Ingenieros, licenciados y asimilados } \\
\text { Ingenieros técnicos, peritos, } \\
\text { ayudantes titulados y asimilados. } \\
\text { Jefes administrativos y de taller y } \\
\text { asimilados. }\end{array}$ \\
\hline 2 & $\begin{array}{l}4 \\
5 \\
6 \\
7\end{array}$ & $\begin{array}{l}\text { Ayudantes no titulados y asimilados. } \\
\text { Oficiales administrativos y asimilados. } \\
\text { Subalternos y asimilados. } \\
\text { Auxiliares administrativos y } \\
\text { asimilados. }\end{array}$ \\
\hline 3 & $\begin{array}{l}8 \\
9 \\
10 \\
11 \\
12\end{array}$ & $\begin{array}{l}\text { Oficiales primera y segunda } \\
\text { asimilados. } \\
\text { Oficiales tercera y especialistas y } \\
\text { asimilados. } \\
\text { Peones y asimilados. } \\
\text { Trabajadores de } 17 \text { años. } \\
\text { Trabajadores menores de } 17 \text { años. }\end{array}$ \\
\hline 4 & 13 & Pensionistas \\
\hline
\end{tabular}

From this original data we construct a panel of gross migration flows. It has 80,000 observations ( 8 biannual dates from 78 to 92 , by 4 qualification groups, by 50 multiplied by 50 province pairs, including the diagonal, which we later ignore. Each observation has the following variables:

FLOW: The actual gross flow from province of origin to province of destination. This is our main dependent variable.

PROVOLD: Province of origin.

PROVNEW: Province of destination.

QOLD: Qualification of flows at province of origin.

TOT: Total number of affiliate workers to the Social Security at the province of origin.

TOTNEW: Total number of affiliate workers at the Social Security in the province of destination.

YEAR: Time variable, with values $78,80,82,84,86,88,90$ and 92 .

YEAR, PROVOLD, PROVNEW and QOLD indexes each observation.

\subsection{Provincial Data}

We use the panel constructed by Fundación BBV. This series comes biannually (odd years). The variables used in our analysis are the following: 
RATAGRI: Ratio between agricultural sector weight in province of origin to agricultural weight in province of destination. Agricultural weight is computed by the ratio of agricultural income to provincial GNP.

RATSER: Ratio between services sector weight in province of origin to services sector weight in province of destination. Services weight is computed by the ratio of agricultural income to provincial GNP.

RENORI: Per capita income of province of origin.

RATEMP: Ratio between employment growth between province of origin and province of destination.

RATWAG: Ratio between wage rate in province of origin to province of destination. Wage rate is computed as total income from workers over number of employed at the provincial level.

RATUNR: Ratio between unemployment rate of province of origin to province of destination.

RATPRV: Ratio between housing prices in province of origin to province of destination. Housing prices is proxied by renting and real estate income over provincial GNP.

The following two tables provide a description of these data:

Provincial Data: Summary Statistics

\begin{tabular}{l|cccc}
\hline \hline Variable & Mean & Std. Dev. & Min & Max \\
\hline RATAGRI & 2.281 & 4.799 & .010 & 90.958 \\
RATSER & 1.033 & .274 & .354 & 2.820 \\
RENORI & 588418.3 & 342722.1 & 121501 & 1887307 \\
RATEMP & 1.001 & .055 & .783 & 1.277 \\
RATWAG & 1.017 & .188 & .517 & 1.933 \\
RATUNR & 1.232 & .906 & .070 & 14.110 \\
RATPRV & 1.028 & .250 & .335 & 2.978 \\
\hline \hline
\end{tabular}

Provincial Data: Correlation Matrix

\begin{tabular}{l|cccccc}
\hline \hline & RATAGRI & RATSER & RENORI & RATEMP & RATWAG & RATUNR \\
\hline RATAGRI & 1.000 & & & & & \\
RATSER & -0.328 & 1.000 & & & & \\
RENORI & -0.066 & 0.064 & 1.000 & & & \\
RATEMP & $0.004^{*}$ & 0.043 & 0.025 & 1.000 & & \\
RATWAG & -0.349 & 0.192 & 0.182 & 0.045 & 1.000 & \\
RATUNR & -0.152 & 0.472 & -0.116 & -0.144 & -0.121 & 1.000 \\
RATPRV & -0.096 & 0.246 & $-0.007^{*}$ & 0.040 & -0.031 & $0.004^{*}$ \\
\hline \hline
\end{tabular}

* Not significant at $5 \%$

Notice that these variables vary with YEAR, PROVOLD and PROVNEW but not with QUAL.

As commented in the text, we use this provincial information with a lag, to reduce endogeneity problems with right-hand variables. So the years corresponding to this variables are $1977,1979,1981,1983,1985,1987,1989$ and 1991. 


\subsection{Distance data}

The distance between provinces, DISVEC, is computed using coordinates from data maps from SAS Institute from approximated centers of the province. This variable varies obviously only with PROVNEW and PROVOLD. 


\section{Appendix 2: Tables and Pictures}

Table 1: Number of migrants over the whole period*

\begin{tabular}{l|ccc}
\hline \hline Category & Total Affiliates & Interregional & Interprovincial \\
\hline Qual. 1 & 62159 & $1418(2.28 \%)$ & $2088(3.36 \%)$ \\
Qual. 2 & 127555 & $2365(1.85 \%)$ & $3175(2.48 \%)$ \\
Qual. 3 & 345969 & $6400(1.84 \%)$ & $8401(2.42 \%)$ \\
Pensioners & 143012 & $1279(0.88 \%)$ & $1629(1.14 \%)$ \\
\hline TOTAL & 678693 & $11453(1.68 \%)$ & $15293(2.25 \%)$ \\
\hline \hline
\end{tabular}

* Total Affiliates is not equal to Total Workers in the sample. See Appendix 1.

Table 2: Rate of immigration and emigration

\begin{tabular}{l|cc}
\hline \hline Category & $\begin{array}{c}\text { Average Immigration } \\
\text { (Std. Dev.) }\end{array}$ & $\begin{array}{c}\text { Average Emigration } \\
\text { (Std. Dev.) }\end{array}$ \\
\hline \hline Qual. 1 & $.048(.041)$ & $.051(.055)$ \\
Qual. 2 & $.032(.023)$ & $.030(.022)$ \\
Qual. 3 & $.027(.017)$ & $.027(.019)$ \\
Pensioners & $.013(.015)$ & $.012(.012)$ \\
\hline \hline
\end{tabular}

Table 3: Correlation matrix of immigration and out-migration rates

\begin{tabular}{l|ccccccc}
\hline \hline & IMRATE1 & IMRATE2 & IMRATE3 & IMRATE4 & EMRATE1 & EMRATE2 & EMRATE3 \\
\hline IMRATE1 & 1.00 & & & & & & \\
IMRATE2 & 0.177 & 1.000 & & & & & \\
IMRATE3 & 0.235 & 0.460 & 1.000 & & & & \\
IMRATE4 & $-0.068^{*}$ & $-0.047^{*}$ & 0.111 & 1.000 & & & \\
EMRATE1 & 0.523 & 0.224 & 0.181 & $-0.077^{*}$ & 1.000 & & \\
EMRATE2 & 0.106 & 0.432 & 0.439 & $0.090^{*}$ & 0.175 & 1.000 & \\
EMRATE3 & 0.207 & 0.475 & 0.825 & 0.169 & 0.153 & 0.396 & 1.000 \\
EMRATE4 & $0.009^{*}$ & -0.169 & -0.105 & $0.046^{*}$ & 0.114 & $-0.018^{*}$ & -0.160 \\
\hline \hline
\end{tabular}

* Not significant at $5 \%$ 
Table 4: Yearly net flows by qualification. Correlation matrix

\begin{tabular}{l|ccc}
\hline \hline & Qual. 1 & Qual. 2 & Qual. 3 \\
\hline Qual. 1 & 1.000 & & \\
Qual. 2 & 0.240 & 1.000 & \\
Qual. 3 & $0.036^{*}$ & -0.141 & 1.000 \\
Pensioners & $-0.091^{*}$ & $-0.013^{*}$ & -0.292 \\
\hline \hline
\end{tabular}

* Not significant at $5 \%$

Table 5: Total net flows by qualification. Correlation matrix

\begin{tabular}{l|cccc}
\hline \hline & Qual. 1 & Qual. 2 & Qual. 3 & Total \\
\hline Qual. 1 & 1.000 & & & \\
Qual. 2 & 0.156 & 1.000 & & \\
Qual. 3 & $-0.000^{*}$ & $-0.058^{*}$ & 1.000 & \\
Pensioners & -0.277 & $0.024^{*}$ & -0.471 & 1.000 \\
\hline Total & 0.179 & 0.574 & 0.604 & 0.111 \\
\hline \hline
\end{tabular}

* Not significant at $5 \%$

Table 6: Total net flows by qualification

\begin{tabular}{l|ccccc}
\hline \hline PROVINCE & Qual. 1 & Qual. 2 & Qual3 & Qual4 & Total \\
\hline BARCELONA & 29 & -76 & -3 & -21 & -71 \\
MADRID & -27 & -91 & 110 & -5 & -13 \\
\hline \hline
\end{tabular}

Table 7: Total gross and net flows by qualification

\begin{tabular}{l|ccc}
\hline \hline MADRID & Inflows & Outflows & Netflows \\
\hline Qual. 1 & 310 & 337 & -27 \\
Qual. 2 & 475 & 566 & -91 \\
Qual. 3 & 878 & 768 & 110 \\
Pensioners & 191 & 196 & -5 \\
\hline \hline
\end{tabular}


Table 8: Negative Binomial Regression for Workers

\begin{tabular}{|c|c|c|c|c|}
\hline "WORKERS & \multicolumn{2}{|c|}{ 1978/1984 } & \multicolumn{2}{|c|}{ 1986/1992 } \\
\hline Flows & Coefficient & Std. Error & Coefficient & Std. Error \\
\hline DISVEC & -1.104 & 0.025 & -1.219 & 0.020 \\
\hline TOT & 0.569 & 0.093 & 0.880 & 0.089 \\
\hline TOTNEW & 0.463 & 0.033 & 0.444 & 0.029 \\
\hline QUAL. 2 & -0.539 & 0.092 & -0.465 & 0.074 \\
\hline QUAL. 3 & -0.709 & 0.191 & -0.803 & 0.158 \\
\hline RATAGRI & 0.124 & 0.034 & 0.277 & 0.031 \\
\hline RETSERV & -1.761 & 0.157 & -2.202 & 0.141 \\
\hline RENORI & $-0.972^{*}$ & 0.513 & -1.666 & 0.528 \\
\hline RATEMP & $-0.536^{* *}$ & 0.380 & -0.635 & 0.301 \\
\hline RATUNR & $0.025^{* *}$ & 0.054 & 0.171 & 0.045 \\
\hline RATWAG.1 & $0.075^{* *}$ & 0.273 & 0.739 & 0.261 \\
\hline RATWAG.2 & 0.523 & 0.247 & 1.222 & 0.234 \\
\hline RATWAG.3 & 0.656 & 0.200 & 1.045 & 0.211 \\
\hline RATPRV & -0.738 & 0.100 & -0.573 & 0.122 \\
\hline Constant & 10.894 & 6.912 & 21.041 & 7.537 \\
\hline $\ln (\alpha)$ & & & & \\
\hline DISVEC & 0.499 & 0.060 & 0.511 & 0.035 \\
\hline TOT & -0.428 & 0.069 & -0.474 & 0.044 \\
\hline TOTNEW & -0.581 & 0.077 & -0.556 & 0.046 \\
\hline QUAL. 1 & -1.666 & 0.283 & -1.577 & 0.158 \\
\hline QUAL.2 & -1.300 & 0.232 & -1.323 & 0.124 \\
\hline Constant & 4.136 & 0.722 & 4.724 & 0.467 \\
\hline $\begin{array}{l}\text { LR test } \\
\text { agains Poisson }\end{array}$ & $P=0.000$ & & $P=0.000$ & \\
\hline Log Likelihood & -9256.319 & & -14049.469 & \\
\hline Number of obs. & 29400 & & 29400 & \\
\hline Model chi2(71) & 5587.78 & & 8947.32 & \\
\hline Prob $>$ chi 2 & 0.000 & & 0.000 & \\
\hline Pseudo R2 & 0.231 & & 0.241 & \\
\hline
\end{tabular}

* Coefficients not significant at $5 \%$ but significant at $10 \%$

** Coefficients not significant at $10 \%$ 
Table 9: Negative Binomial Regression for Pensioners

\begin{tabular}{|c|c|c|c|c|}
\hline "PENSIONERS & \multicolumn{2}{|c|}{$1978 / 1984$} & \multicolumn{2}{|c|}{$1986 / 1992$} \\
\hline Flows & Coefficient & Std. Error & Coefficient & Std. Error \\
\hline$\overline{\text { DISVEC }}$ & -1.072 & 0.062 & -1.078 & 0.050 \\
\hline TOT & 0.806 & 0.373 & 1.814 & 0.637 \\
\hline TOTNEW & 0.400 & 0.082 & 0.394 & 0.075 \\
\hline RATAGRI & 0.234 & 0.081 & 0.397 & 0.072 \\
\hline RETSERV & -1.086 & 0.382 & -1.834 & 0.319 \\
\hline RENORI & $-0.719^{* *}$ & 1.271 & -3.241 & 1.373 \\
\hline RATEMP & -2.766 & 0.946 & -2.832 & 0.822 \\
\hline RATUNR & $0.089^{* *}$ & 0.15 .5 & $0.157^{* *}$ & 0.117 \\
\hline RATWAG & $-0.343^{* *}$ & 0.480 & 0.997 & 0.456 \\
\hline RATPRV & -2.033 & 0.288 & -0.688 & 0.305 \\
\hline Constant & $3.843^{* *}$ & 17.082 & $36.129^{* *}$ & 20.222 \\
\hline$\overline{\ln (\alpha)}$ & & & & \\
\hline DISVEC & 0.746 & 0.167 & 0.452 & 0.157 \\
\hline TOT & $-0.032^{* *}$ & 0.169 & -0.766 & 0.237 \\
\hline TOTNEW & -0.675 & 0.220 & -0.923 & 0.269 \\
\hline Constant & $0.446^{* *}$ & 1.791 & 8.020 & 2.269 \\
\hline $\begin{array}{l}\text { LR test } \\
\text { agains Poisson }\end{array}$ & $\mathrm{P}=0.000$ & & $P=0.000$ & \\
\hline Log Likelihood & -1778.895 & & -2336.274 & \\
\hline Number of obs. & 9800 & & 9800 & \\
\hline Model chi2(65) & 1162.31 & & 1456.66 & \\
\hline Prob $>$ chi 2 & 0.000 & & 0.000 & \\
\hline Pseudo R2 & 0.246 & & 0.237 & \\
\hline
\end{tabular}

* Coefficients not significant at $5 \%$ but significant at $10 \%$

** Coefficients not significant at $10 \%$ 


\section{References}

[1] Aguirregabiria V., Alonso-Borrego C. (1998), "Labor Contracts and Flexibility: Evidence from a Spanish Labor Market Reform", mimeo.

[2] Antolin P., Bover O. (1997), "Regional Migration in Spain: the Effect of Personal Characteristics and of Unemployment Wage and House Price Differentials Using Pooled Cross-Sections", Oxford Bulletin of Economics and Statistics, vol. 59, n. 2.

[3] Bean C., Bernholz P., Danthine J. P., Malinvaud E. (1990), "European Labour Markets: a Long-run View", Brussels, Center for European policy Studies.

[4] Bentolila S., Dolado J. J. (1991), "Mismatch and Internal Migration in Spain, 196286", in Padoa Schioppa F. (ed.) "Mismatch and Labour Mobility", Cambridge University Press, Cambridge.

[5] Bentolila S., Jimeno J. F. (1995), "Regional Unemployment Persistence (Spain, 197694)", CEPR Discussion Paper n. 1259.

[6] Burda M., Wyplosz C. (1992), "Human Capital, Investment and Migration in an Integrated Europe", European Economic Review, no. 36.

[7] Cardelús-Farré M. T.(1993), "Cuentas de Cotización de la Seguridad Social (1993)", Centro de Estudios Avanzados en Economía, Documento de Trabajo n. COD-93/03.

[8] Castillo S., Jimeno J. F., Licandro O. (1998), "Employment Segmentation, Labour Mobility, and Mismatch: Spain 1987-1993", FEDEA, Documento de Trabajo n. 9804 .

[9] Congdon P. (1993), "Approaches to Modelling Overdispersion in the Analysis of Migration", Environment and Planning, vol. 25.

[10] Devillanova C. (1998), "Migration Flows and Interregional Labor Market Disequilibrium", Econpubblica, Università Bocconi , Milano, n. 56.

[11] Feder G. (1980), "Alternative Opportunities and Migration: Evidence from Korea", Annals of Regional Science, n. 14.

[12] Flowerdew R. (1991), "Poisson Regression Modelling of Migration", in Stillwell J., Congdon P., Editors, "Migration Models: Macro and Micro Approaches", Belhaven Press, London.

[13] Foot D. K., Milne W. J. (1990), "Serial Correlation in Multiregional Migration Models", Journal of Regional Science, vol. 30, n. 4. 
[14] García-Fontes W., Hopenhayn H. (1995a), "Componentes Cíclicos y Cambio Estructural en la Destrucción de Empleo", in Marimon R., "La Economía Española: una visión Diferente", cap. 6, A. Bosch.

[15] García-Fontes W., Hopenhayn H. (1995b), "Flexibilización y Volatilidad del Empleo", Moneda y Credito, n. 202.

[16] Garcia-Perez J. I. (1997), "Las Tasas de Salida del Empleo y el Desempleo en España (1978-1993), Investigaciones Economicas, vol. 21, n. 1.

[17] Ghatak S., Levine P., Wheatley Price S. (1996), "Migration Theories and Evidence: an Assessment", Journal of Economic Survey, vol. 10, n. 2.

[18] Gordon I. (1991), "Multi-Stream Migration Modelling", in Stillwell J., Congdon P., Editors, "Migration Models: Macro and Micro Approaches", Belhaven Press, London.

[19] Greenwood M. J. (1975), "Research on Internal Migration in the United States: A Survey", Journal of Economic Literature, vol. 13.

[20] Greenwood M. J. (1993), "Migration: A Review", Regional Studies, vol. 27, n. 4.

[21] Greenwood M. J. (1997), "Internal Migration", in Rosenzweig M. R., Stark O. (eds.), Handbook of Population and Family Economics, vol. 1B.

[22] Herzog H. W., Schlottmann A. M., Boehm T. P. (1993), "Migration as Spatial JobSearch: a Survey of Empirical Findings", Regional Studies, vol. 27, n.4.

[23] Hughes G., McCormick B. (1994), "Did Migration in the 1980s Narrow the NorthSouth Divide?", Economica, vol. 61, n. 244

[24] Jackman R., Savouri S. (1992), "Regional Migration in Britain: an Analysis of Gross Flows Using NHS Central Register Data", The Economic Journal, n. 102.

[25] Jimeno J. F. (1997), "Los Factores Específicos del Paro en Andalucía", FEDEA, Documento de Trabajo 97-05..

[26] Milne W. (1991), "The Human Capital Model and its Econometric Estimation", in Stillwell J., Congdon P., Editors, "Migration Models: Macro and Micro Approaches", Belhaven Press, London.

[27] Molho J. (1984), "A dynamic Model of Interregional Migration Flows in Great Britain", Journal of Regional Science, vol. 24, n. 3.

[28] Olano Rey A. (1990), "Las Migraciones Interiores en fase de Dispersion", Revista de Economia y Sociologia del Trabajo, n. 8-9, September. 
[29] Ródenas Calatayud C. (1994), "Emigracion y Economia en España", Universidad de Alicante, Editorial Civitas.

[30] Segura J., Durán F., Toharia L., Bentolila S. (1991), "Análisis de la Contretación Temporal en España", Ministerio de Trabajo y Seguridad Social, Madrid.

[31] Shioji E. (1995), "Regional Growth in Japan", Economics Working Paper, Universitat Pompeu Fabra, no. 138.

[32] Vanderkamp J. (1977), "The Gravity Model and Migration Behaviour: an Economic Interpretation", Journal of Economic Studies, vol. 4, n. 2.

[33] Winkelmann R., Zimmermann K. F. (1995), "Recent Developements in Count Data Modelling: Theory and Application", Journal Of Economic Surveys, vol. 9, n. 1. 